\title{
Neurobiological and Psychological Mechanisms Explaining How Hatred is Programmed into the Minds of Children
}

\author{
G.H. Katzman* \\ Midwest Health Center Pediatrics, Dearborn, Michigan 48126, USA
}

\begin{abstract}
An understanding of the mechanisms involving the programming of hatred into the minds of children has evolved. Indoctrination of children with storylines that are often fabrications is common. The animosities engendered by these stories are fueled by anger frequently associated with mental or physical maltreatment of children in authoritarian societies. Studies indicate that the dominant premotor areas of the brain are important for moral decision making and cognitive control. Eliminating destructive indoctrination, prevention of child abuse and inculcating children with values that promote peaceful human relations have the potential for eliminating the development of hatred and the associated acting out of violent behaviors.
\end{abstract}

Keywords: Neurobiology \& psychology of hate, social cognition, moral judgment.

\section{INTRODUCTION}

It has been suggested that the "Psychological Descent into Violence [1]" is associated with a continuum of attitudes that progress from simple bias, to prejudice, to bigotry and finally to hatred [2]. It is only when hatred is developed in the minds of individuals that there is the likelihood of premeditated violence directed against a particular target group. Hatred is an emotion or passion and a form of delusional thinking [2]. It requires an object, the choice of which may be rational or irrational [2]. Recent research provides insight into the psychological and neurobiological mechanisms leading to tunnel vision hatred [3-6]. It is hopefully through the enhanced understanding of these mechanisms that remedies can be developed to counter the programming of persons to hate. Instituting these remedies, could help avoid the irreversible compromise in the lives of those taught to hate and their victims.

\section{THE NEOCORTEX AND THE LIMBIC SYSTEM}

The increased volume of the cerebral cortex of Homo sapiens provides the potential for more complex cognitive functions than other species. Studies using fMRI indicate that mature decision making is largely dependent on cortical functions involving mainly the prefrontal areas [7]. The more primitive limbic structures, the hippocampus and amygdala play an important role in affective responses [4]. The hippocampus functions to form and retrieve both verbal and emotional memories, whereas the amygdala creates the emotional content of memory (i.e. fear and aggressive responses). The concept of the prefrontal cortex modulating output from the more primitive brain areas seems fairly well established, all be it a probably over simplified concept [7]. It is, however, important to point out that prefrontal activity can either enhance or suppress limbic urges. How the

*Address correspondence to this author at the Midwest Health Center Pediatrics, Dearborn, Michigan 48126, USA; E-mail: geraldktzm@aol.com prefrontal areas are programmed and function will ultimately determine person to person and person to group behaviors.

\section{The Early Years}

There is a growing body of evidence that psychological insults in the first several years of life can have undesirable consequences [4]. Critical brain structures are often irreversibly altered by exposure to physical, emotional or sexual abuse. Imaging studies have demonstrated that structures involving the limbic system are often diminished in size, probably secondary to the effect of stress hormones. These structures include the amygdala, the hippocampus and the vermis of the cerebellum. The middle part of the corpus callosum also is smaller than expected. The functional result of these changes seems to be a "hyper excitable" limbic system primed to respond to "fight or flight" with minimal sensory input. Such a neurophysiologic setup may have been adaptive for survival in primitive times but is clearly a hindrance to thoughtful interpersonal relationships.

In addition to adversely altering brain structure and physiology, psychological maltreatment creates a feeling of intense anger in the abused towards the abuser or abusers [5]. This anger which is often suppressed in authoritarian societies due to the realistic fear of immediate retribution should be expressed. Nonetheless, a channel for expression of this anger may later result in the victimization of others.

\section{SOCIAL COGNITION AND THEORY OF MIND}

Social cognition refers to the ability to know how the social world actually works [8]. By four years of age, children have developed an appreciation as to what behaviors will meet with approval by adults and their playmates and what actions will get them into trouble. This skill or "theory of mind" continues to develop as the child matures [9]. Interestingly, social cognition varies from culture to culture.

Studies in socio-cultural anthropology have demonstrated dramatic differences in behavioral expectations from 
members of different societies. For example, the Sambia from New Guinea have been studied extensively [10]. Typically, Sambian boys were separated from their families at an early age. They were placed in a situation where submission to forced homosexuality was demanded. Deviation from this expected behavior, resulted in harsh physical discipline. Empathy was actively discouraged. Young males were also subjected to violent initiation rites. An example of such a rite was nose bleeding, carried out by the thrusting of grass reeds into the initiates' noses by elders. These practices were apparently designed to develop fierce ruthless warriors and "prepare" Sambian boys to function in future heterosexual marriage. This culture continued for hundreds of years, until missionaries intervened to try and modify many of these practices that seemed inhumane. Interestingly, parallels can be seen between the Sambian culture and that of the Spartans of Ancient Greece [11] who are also remembered as great fighters.

Contrary to Sambian and Spartan societies, there are examples of cultures and traditions that seem to promote "Western" values. Such moral qualities as reverence for the value of all human life, charity, respect for individual differences and peaceful resolution of disputes are examples of the ethical goals of the learning that is transmitted [12, 13]. Usually, positive reinforcement is the main mechanism by which the children in these cultures are assisted to mature in their thinking. Eventually, children so oriented generally become mutually supportive caring human beings who are anxious to contribute to society in the context of their learning. Suppressed anger does not commonly seem to be a motivating emotion in these societies.

\section{SPLITTING AND THE PARANOID SHIFT}

It is clear from anthropological studies that human beings can be "sold a bill of goods" during growth and development. Stories propagated from childhood are accepted as truth, even though objective observers often marvel at the preposterous nature of some of the "learned" scenarios [14-16]. Should the storyline portray the members of a society as victims of another group, then the stage is set for the full expression of the psychological defense mechanism of splitting [5]. As described by Burdman, splitting has its roots in the buried emotions of childhood trauma. Moreover, splitting is a process "whereby antagonistic feelings toward the parent and toward the individual himself continue as a damned up source of predominately subconscious anger" [5]. Later, this anger is discharged by projection outward onto a socially endorsed target.

In a concept similar to splitting, Gaylin has described the paranoid shift as an important mechanism for hatred development [3]. The process starts with anger that evolves into "an enduring organization of aggressive impulses toward a person or toward a class of persons" [17]. This hatred is "composed of a habitual bitter feeling and accusatory thought. ... The hater is sure that the fault lies in the object of his/her hatred" [17]. This is what has classically been termed projection. However, the term paranoid shift emphasizes the centrality of the false belief component of the process. Apparently, "so long as he believes this, he will not feel guilty for his uncharitable state of mind" [17]. This lack of guilt allows the hater to act out aggression against the targeted person or group without emotional pain.

\section{THE BRAIN IN MORAL JUDGMENT, HATRED AND VIOLENCE}

According to Eslinger et al. "moral judgment is a higher order type of social decision-making that draws heavily on cognitive and emotional empathetic processes" [18]. In their studies using fMRI, moral judgments strongly activated bilaterally the frontopolar cortex (FPC) and the medial frontal gyrus (MFG). The right anterior temporal cortex, lenticular nucleus and cerebellum were also significantly activated but differently from the FPC and MFG. These brain regions were strongly influenced by emotional experience. Thus, there is support for Goleman's concept of the "High Road" and "Low Road" [19]. Specifically, the dominant premotor frontal areas are largely responsible for cognitive control and can override the more primitive implicit limbic system and non-dominant cortical emotional output.

Viewing a hated face activates several brain areas [6]. These include the medial frontal gyrus, right putamen, bilaterally in the premotor cortex, in the frontal pole and bilaterally in the medial insula. The level of hatred correlates linearly with activity in the right insula, right premotor cortex and the right fronto-medial gyrus. The involvement of frontal areas in the instance of targeted hatred is of interest, since this area is also activated in moral judgments. It does seem that there would be the possibility of programming the dominant frontal areas with information that would inhibit the expression of hatred.

Individuals who have inflicted physical harm on others have also been studied with fMRI [20]. Murderers were found to have a high incidence of reduced prefrontal activity, suggesting that prefrontal dysfunction may underlie a predisposition to violence. Of interest, is the fact that excessive subcortical activity was most common in patients with a history of intense violent behaviors. So, a situation of reduced "high road" and increased "low road" activity commonly characterizes these perpetrators of violence.

\section{NURTURING THE HEALTHY GROWTH AND DEVELOPMENT OF CHILDREN}

It appears that indoctrination to particular scenarios provides the vehicle for hatred that is fueled by dammed up anger from early childhood experiences. That is not to say that the storylines generating various false beliefs could not in and of themselves produce high levels of animosity toward specific individuals and groups. Logically, this present understanding of the pathophysiology of hatred, should lead to initiatives to counter the process.

Certainly the prevention of childhood psychological, physical and sexual abuse, could contribute to efforts to counter future violent behavior. Unfortunately, there are authoritarian societies where these kinds of mental and physical maltreatments are part and parcel of the culture [21]. Parents, schools and local and national authorities can be implicated as the source of such maltreatment. Changing the modus operandi of these individuals and agencies to more emotionally supportive functions would seem critical. Suggestions as to who should identify these problems and 
initiate solutions, has been addressed previously and requires urgent consideration [22].

The teaching of storylines that distort history, promote false beliefs and propagate negative feelings toward particular ethnic or racial groups for political purposes creates a major problem. The lowering of negative emotional biases against individuals and groups has been shown to lessen conflict [23]. Stories that have no real basis in fact need to be countered with exposure to objective truths, before they serve as the underpinning for intergroup conflict. The moral basis for countering these storylines and promoting peaceful human relations through educational programs can be readily justified [22].

Many politically motivated storylines promote aggression without reverence for the value of human life, regard for individual freedoms or promotion of the optimal psychosocial development of children. There are stories that incorrectly depict one group as a victim of another. Other narratives promote the heretical nature of targeted groups. Still other anecdotes, contrived because of desires for dominance, undermine the humanity of those to be victimized. Children deserve better than to be exposed to these kinds of scenarios that frequently result in future violent immoral behaviors and destroy potentially productive lives.

If the mental and physical maltreatment of children and the indoctrination to false beliefs were stopped, the development of hatred in children could be virtually eliminated. Efforts to achieve such a goal should be a prime subject that organizations and governments that have the responsibility to be advocates for children should urgently address.

\section{REFERENCES}

[1] Gaylin W. Hatred: The psychological descent into violence. New York: Cover, Public Affairs ${ }^{\mathrm{TM}}$, Perseus Books Group 2003.

[2] Gaylin W. Hatred: The psychological descent into violence. New York: Public Affairs ${ }^{\mathrm{TM}}$, Persus Books Group 2003; pp. 23-9.
[3] Gaylin W. Hatred: The psychological descent into violrnce. New York: Public Affairs ${ }^{\mathrm{TM}}$, Persus Books Group 2003; pp. 36.

[4] Teicher MH. Scars that won't heal: the neurobiology of child abuse. Sci Am 2002; 286: 68-75.

[5] Burdman D. Hatred of the Jews as a psychological phenomenon in Palestinian society. Available at: www.think-israel.org/burdman. jewhatred.html. Accessed 10/10/2007.

[6] Zeki S, Romaya JP. Neural correlates of hate. Available at: www.plosone.org/article/info:doi/10.1371/journal.pone.0003556. Accessed 11/15/2008.

[7] Hare TA, Casey BJ. The neurobiology and development of cognitive and affective control. cognitie, creier, comportament/ cognition. Brain Behavior 2005; 9(3): 273-86.

[8] Goleman D. Social intelligence. New York: Bantam Book 2006: pp. 84 .

[9] Goleman D. Social intelligence. New York: Bantam Book 2006; pp. 134-8.

[10] Herdt G. The Sambia Ritual and Gender in New Guinea. Harcourt Brace Jovanovich College Publishers 1987.

[11] Cartledge P. The Spartans: The world of the warrior-heroes of ancient Greece. New York: Vintage Books 2004.

[12] Zborowski M, Herzog E. Life is with people: the culture of the shtetl. New York: Schocken Books 1962.

[13] Baha'is tackles challenges of a world at risk. www.bahai.us/node/ 176. Accessed 07/17/2009.

[14] Mills M. Propaganda and children during the Hitler years. www.jewishvirtuallibrary.org/jsource/Holocaust/propchil.html. Accessed 07/21/2009.

[15] Verghese BG. Myth and hate as history. www.thehindu.com/2004/ 06/23/stories/2004062301721000.htm. Accessed 07/21/2009.

[16] Children indoctrinated with antisemitism on an Egyptian-Saudi Koran-memorization channel. www.memritv.org/clip/en/2106.htm. Accessed 07/21/2009.

[17] Allport GW. The nature of prejudice. Garden City, New York: Doubleday Anchor Book 1958; pp. 341.

[18] Eslinger PJ, Moll J, Oliveira-Souza R. Emotional and cognitive processing in empathy and moral behavior. Behavioral and Brain Sciences 2002; 25(1): 34-5.

[19] Goleman D. Social Intelligence. New York: Bantam Book; 2006; 321-2.

[20] Bufkin JL, Luttrell VR. Neuroimaging studies of aggressive and violent behavior. Trauma Violence \& Abuse 2005; 6(2): 176-91.

[21] Khamis V. Child psychological maltreatment in Palestinian families. Child Abuse Neglect 2000; 24(8): 1047-59.

[22] Katzman G. A bioethical analysis of a form of psychologic abuse: teaching hatred to children. Clin Pediatr 2005; 44(2): 143-50.

[23] Goleman D. Social intelligence. New York: Bantam Book 2006; pp. 302-4. 